\title{
TÉCNICAS DE NEUTRALIZACIÓN: una teoría de la delincuencia ${ }^{1}$
}

\author{
G resham M'Cready Syk es* \\ D avid Matza*
}

En un intento por descubrir las raíces dela delincuencia juvenil, los científicos sociales abandonaron hace ya tiempo la búsqueda de "demonios en la mente" o de "estigmas en el cuerpo". En la actualidad, se cree que el comportamiento delictivo, como casi todo comportamiento social, es una conducta que se aprendeen el proceso deinteracción social.

El planteo clásico que da cuenta de esta posición seencuentraen la teoría delaasociación diferencial de Sutherland, que establece que el comportamiento criminal o delictivo implica el aprendizaje de: a) técnicas para cometer delitos, y b) motivos, impulsos, racional izacionesy actitudes a favor del incumplimiento dela ley (Sutherland, 1995, p.77-80). Desafortunadamente, seha prestado poca atención al contenido específico delo que

* Doutor na Universidade de Northwestern. Professor of Sociology Emeritus da University of Virginia.

** Ph.D. Princeton University. Professor Emeritus do Departamento de Sociologia da Universidade de Berkel ey (1960-1999).

1 Texto original na American Sociological Review. Columbus,OH, v. 22, n. 4, p. 664-670, ago., 1957. Tradução: María Florencia Vaquero. Delito y Sociedad, Buenos Aires, v. 13, n. 20, 2004. se aprende (en oposición al proceso a través del cual algo seaprende) tanto en la teoría como en la investigación. Tal vez, la única escuela de pensamiento importanteorientada a comprender la natural eza de este conteni do se haya centrado en la idea de una subcultura delictiva. La característica principal de una subcultura delictiva, se sostiene, es ser un sistema de valores que representa la inversión de los valores de una sociedad respetable que se somete a la ley. El mundo del delincuenteesel mundo del sometimiento alaley puesto de cabeza, y sus normas constituyen un contrapeso dirigido contra el orden social que sí cumplecon la ley (Cohen, 1955). Cohen consideraqueel proceso de desarrollo deunasubcultura delictiva es el resultado de la construcción, el mantenimiento y el reforzamiento de pautas de conducta que existen por oposición a los val ores dominantesy queestán en total contradicción con éstos, y en particular, con los dela clasemedia. El retrato de la delincuencia que dibuja Cohen presenta un al to grado de sofisticación; cautelosa mente, se evitan explicaciones simples, como aquellas quese basan en el principio de "imitar al 
líder", y generalizaciones livianas, querefieren a "problemas emocionales". Asimismo, no acepta la subcultura delictiva como al go dado, sino que, por el contrario, sistemáticamenteanaliza la función delosvalores delictivos como una solución posible a los problemas de los jóvenes menores de clase bajaen relación con su posición social. Sin embargo, y a pesar de sus virtudes, esta imagen de la delincuenciajuvenil como formadecomportamiento basado en el contrapeso o la rival idad deval oresy normas, parece contener graves errores. Esteartículo precisamente trata de la natural eza de estos defectos y deposibles explicaciones al ternativaso diferentes que den cuenta degran partedelo que implicaladelincuenciajuvenil.

Las dificultades de considerar al comportamiento delictivo como el fruto deun conjuntodeval oresynormas desviadas (en otras palabras, como el resultado de una situación en la que el delincuentedefineel delito quecometiócomo “justo") son de carácter empírico y teórico. En primer lugar, si dehecho existierauna subcultura delictiva en función dela cual el delincuenteconsiderarasu comportamiento ilegal como moralmentecorrecto, podríamos suponer que el delincuente no manifestaríasentimientosni deculpani devergüenza en su detención o encierro; por el contrario, la principal reacción se manifestaría como indignación o un sentimiento de martirio. ${ }^{2} \mathrm{Si}$ bien es cierto que algunos delincuentes reaccionan de este modo, el sentimiento demartirio, por logeneral, parecebasarse en el hecho dequeotros "zafaron", mientras quela indignación parecedirigirsecontralosacontecimientos y lafalta decapacidades quelo llevaron al encierro. Sin embargo, resulta aún más importanted hecho dequeexisten numerosas pruebasquesugieren que muchos delincuentessí experimentan un sentimiento deculpao vergüenzay su manifestación externa, no debe desestimarse como gesto puramente

2 Esta forma de reacción entre los miembros de una subcultura desviada, que creen en lo "correcto" de su comportamiento y que son capturados y castigados por los organismos del orden social dominante, puede ilustrarse, tal vez, por grupos como los Testigos de Jehová, por las primeras sectas cristianas, por movimientos nacionalistas en regiones que son colonias o fervientes opositores a la Primera y Segunda Guerra Mundial. manipulador paraapaciguar alasautoridades. Seguramente muchas de estas pruebas son de carácter clínico o derivan de opiniones "impresionistas", y fueron proporcionadas por quienes deben tratar en formadirectacon el joven delincuente. Si pretendemos asignarlecierto peso a estas pruebas, debemos ser cuidadosos; no obstante, no podemos ignorarlas si pretendemos evitar caer en el estereotipo burdo del delincuentejuvenil representado comoel gangster mal o en miniatura.

En segundo lugar, através deobservaciones, seadvirtió que los delincuentes juveniles suel en profesar admiración y respeto por las personas que cumplen con laley. Los "realmentehonestos" suelen ser venerados, y si el delincuentees muy perspicaz para detectar cierta hi pocresía en quienes acatan la ley, probablementelaindiscutida honradez ganeel reconocimiento del delincuente Los víncul osfuertes con madres humildes y devotas, o con sacerdotes rectos y clementes (de acuerdo a muchas observaciones, el primer caso sueleestar presente tanto en delincuentes jóvenes como adultos), pueden ser descartados por considerarse expresiones sentimentales; sin embargo, esto demuestra queel del incuente no necesariamente concibecomo inmoral es a quienes sesometen a las reglasjurídicas. Demodo similar, puededestacarse queel delincuentejuvenil puedemanifestar un profundo resentimientosi seatribuyeal guna conducta ilegal a "otrosmiembrosimportantes" dentro desu entornosocial inmediato o ahéroes del mundo del deportey del entretenimiento. En otras palabras, si el delincuenteadscribeaun conjunto deval oresy normas queson total menteopuestosalos valoresy las normas de la sociedad respetable, su forma de observancia deestas normas revisteun carácter pe culiar. Aún cuando supuestamenteel delincuente juvenil acuerda por completo con el sistema desviado de la subcultura delictiva, en muchas circunstancias parecería reconocer lavalidez moral del sistemanormativo dominante. ${ }^{3}$

\footnotetext{
${ }^{3}$ Como advirtió Weber, un Iadrón puede reconocer la legitimidad de las normas legal es sin aceptar su validez moral Marx Weber (1947, p.125). Sin embargo, en este artículo argumentamos que el del incuente juvenil suele reconocer tanto la legitimidad del orden social dominante como su "validez" moral.
} 
En tercerolugar, varias pruebas demuestran que el delincuente juvenil, por lo general, traza una línea tajante entre quienes pueden ser victimizados y quienes no. A ciertos grupos sociales no selos percibe como "jugadores honestos" dentro del juego de las prácticas delictivas supuestamenteaprobadas, mientras que, por otro lado, sejustifica una gran variedad deataques en otros grupos. En general, la potencialidad de victimización parecería ser una función del distanciamiento social entre los delincuentes juveniles y los otros, y, por lo tanto, encontramos máximas explícitas dentro del mundo de la delincuenciatales como "no robarseentreamigos" o "no cometer actos de vandalismo contra una iglesia detu propio credo". Esto pareceobvio, pero sus implicancias no han recibido suficiente atención. El hecho de que el comportamiento supuestamentebasado en ciertos val ores tiendaa dirigirse contra otros grupos sociales cuyos comportamientos no se basan en val ores sugiere quelos delincuentes reconocen la "mal dad" desu comportamiento delictivo muchomásampliamente delo quela literatura da cuenta. Los casos en los que se limita el conjunto de víctimas en función derelaciones de parentesco, amistad, grupo étnico, clase social, edad, género, entre otros, nos permiten pensar que, en realidad, las "ventajas" dela delincuencia nuncason "indiscutibles".

En cuarto lugar, existen dudas respecto del hecho dequemuchos delos delincuentes juveniles sean totalmente inmunes a las demandas de conformidad del orden social dominante. Esmuy probable que la familia del delincuente esté de acuerdo con la sociedad respetableacerca de que la delincuencia es al go malo, aún cuando dicha familia probablemente esté inmersa en varias actividadesilegales. Es decir, la postura dequelos padres conducen a la del incuencia no puede ser un impulso absoluto. Cualquiera seala influencia que ejerce el ejemplo de los padres, lo que podríamos denominar el patrón "Fagin" 4 de

\footnotetext{
${ }^{4}$ Factor Fagin: modo de socialización donde el "mentor" cumple satisfactoriamente las funciones de transmitir pautas de comportamiento pero que son inapropiadas. El término Fagin refiere a un personaje dela novela Oliver
}

socialización, que conduce ala delincuencia, no es frecuente. Incluso, como lo indicó Redl, la idea de que ciertos barrios sean totalmente delincuenciales y ofrezcan a losjóvenesun modelo de comportamiento delictivo, sin excepción, simplemente no se sostiene por la información obtenida (Kobrin, 1951, p.653-661).

El hecho dequeun chico sea castigado, por su comportamiento delictivo, por sus padres, en el colegio o por los organismos del sistema legal, puede sugerirle quela próxima vez debeser más cuidadoso para que no lo atrapen, tal como recalcaron muchos observadores con cierto cinismo. Sin embargo, hay una probabilidad mayor o igual dequeel chico internalicelas demandas de conformidad. Esto no significa quedichas demandas no puedan ser neutralizadas. Dehecho, como veremos más adelante, entender cómo se neutral izan las demandas internas y externas de conformidad puede ser crucial para entender el comportamiento delictivo. Pero esto significa que esimprobablequeseproduzcauna negación completadelavalidez delas demandas deconformidad y que se las sustituya por un nuevo sistema normativo, en virtud dela dependencia del chico o del adolescenterespecto de los adultos y de su vinculación con ellos, inherente a su posición dentro de la estructura social. No importa cuán inmerso estéen los patrones deconducta delictiva, ni tampoco importael grado en quedicho vínculo pueda pesar más que sus vínculos con quienes cumplen con la ley, el joven no deja de condenar las conductas desviadas. Cual quiera sea el modo, las demandas deconformi dad deben ser satisfechas y se les debe dar una respuesta; no pueden ignorarse por pertenecer a un sistema extraño de valoresy normas.

En suma, la postura teórica que consi dera que tanto la delincuencia juvenil como el comportamiento deobediencia dela ley sebasan en normas y valores de unasubcultura delictivay de la sociedad en su conjunto, respectivamente,

Twist de Charles Dickens. Fagin es el jefe de una banda de del incuentes en la que se inserta Oliver y aprende el "oficio de robar" N. del T. 
genera varias dudas. El hecho de que el mundo del delincuente encaje en el mundo de quienes cumplen la ley no sedebepasar por al to, así como no se puede situar al delincuente juvenil en el mismo nivel de un adul to que ya ha sido socializado en un modo devida diferente. Por el contrario, el delincuentejuvenil pareceríaal menosacordar con el orden social dominante en tanto suele manifestar culpa o vergüenza cuando viola las prescripciones de este orden, o al aprobar ciertas representaciones deaceptación, y distinguir entre objetos apropiados e inapropiados de su desviación. Ahora nos dedicaremos a tratar de encontrar una explicación para esteaspecto dela delincuenciaaparentementeparadójico.

Como sostiene Morris Cohen, uno de los problemas más fascinantes del comportamiento humano es el por quélos hombres violan la ley en laquecreen. Esteproblemaesel quesenospresenta cuando tratamos de explicar por qué surge la delincuencia, a pesar del compromiso, mayor o menor, con losmodosusuales deconformidad. Una guía fundamental nos la proporciona el hecho de que las reglas o normas sociales que exigen un comportamiento conformeaval ores casi siempre, sino siempre, seformulan en términos categóricos e imperativos. Es más, los val ores y las normas se presentan comoguías paralaacción contextualizadas y deaplicabilidad limitada en función del tiempo, del espacio, de otros individuos y de las circunstancias sociales. El principio moral que desaprueba el acto de matar, por ejemplo, no rige parael enemigo en combateen tiempos deguerra, a pesar dequela prohibición sevuel veotra vez válida para un enemigo que se toma prisionero. De manera similar, muchos consideran justo la apropiación y distribución de bienes escasos en tiempos de profunda necesidad social, a pesar de que, en otras circunstancias sociales, la propiedad privadaseconsidereinviolable. Por lo tanto, el sistemanormativo de una sociedad secaracteriza por lo queWilliams definió como flexibilidad; no consisteen un conjunto dereglas queseconsideran de cumplimiento obligatorio en todas lascircunstancias (WilliamsJr, 1951, p.28).
Esta flexibilidad, dehecho, es inherenteal derecho penal, en el sentido de que existen "atenuantes deculpabilidad" quepueden promoverse en las declaraciones de cul pabilidad o inocencia del acusado, como, por ejemplo, minoría deedad, necesidad, demencia, ebriedad o defensa propia, entre otros. Se puede evitar la declaración de cul pabilidad moral por un delito - y, deestemodo, evitar las sanciones negativas de la sociedad - si puede probarselafaltadeintención. Creemos que gran parte de los delitos se basan en lo que constituye esencialmente una prolongación delos atenuantes de culpabilidad quese manifiestan como justificaciones dela desviación que son válidas para los delincuentes, pero no para el sistema legal ni para la sociedad en su conjunto. Estas justificaciones comúnmente se describen como racionalizaciones. Se considera que surgen con posterioridad al comportamiento desviado, como un modo de protección del individuo contra su propio sentimiento de cul pa o contra la cul pa de otros luego de haber cometido el delito. No obstante, existen razones para creer que, en realidad, preceden al comportami ento desviado y lo hacen posible. Sutherland menciona al pasar esta posibilidad, la cual aún tampoco ha sido anal izada por otros teóricos desde una perspectiva sociológica. La desaprobación que resul ta dela internalización de las normas y que satisface a otros, en el entorno social, seneutral iza, seda vuel ta o se aparta de antemano. Los controles sociales que sirven para controlar o inhibir patrones motivacional es de desviación resultan ineficaces, y un individuo puede entrar en la del incuencia sin quesedeteriorela imagen quetienedesí mismo. En este sentido, el delincuente "no puede tenerlo todo, tiene que elegir", en tanto continúa entregado al sistemanormativo dominante, pero restringe los mandatos de estesistema y consi dera quelas violaciones son "aceptables", si no "correctas".

Por lo tanto, el delincuente no representa una oposición radical con la sociedad quecumple la ley, sino que parece más un fracaso por el que hay que arrepentirse y que suele ser condenado por los otros, más que por el mismo del incuente. 
Denominamos a este tipo de justificaciones del comportamiento desviado como técnicas de neutralización. Creemos que dichas técnicas constituyen un componente esencial de las "definiciones favorables para el incumplimiento delaley" deSutherland. Esatravés del aprendizaje deestas técnicas queun joven seconvierteen un delincuentejuvenil, y no a través del aprendizaje deimperativos morales, valores o actitudes en total contradicción con aquellos de la sociedad dominante. Al analizar estas técnicas, nos pareció convenientedividirlas en cinco grandes tipos.

La negación dela responsabilidad. Mientras el delincuente no se defina a sí mismo como responsable de sus acciones desviadas, la desaprobación de uno mismo o de otros pierde efectividad como influenciarepresiva. Como el juez Holmes mencionara, incluso un perro distingue un tropiezo deuna patada; y lasociedad moderna no es menos cuidadosa al trazar la línea entre aquellos daños que son culposos (no intencionales), por ejemplo, cuando falta la responsabilidad, y aquellos que son dolosos (intencionales). Como técnica deneutral ización, no obstante, la negación de la responsabilidad se extiende más allá de al egar que los actos desviados son un "accidente", o incluso más allá de cualquier otra negación de la responsabilidad personal similar. También puedemencionarseque las acciones del delincuente se deben a fuerzas ajenas y que están fuera de su control, como, por ejemplo, la carencia de afecto de los padres, las mal as compañíaso vivir en barrios bajos. Dehecho, el delincuente propone una concepción de sí a través de la cual se percibe como impulsado inevitablementea nuevas desviaciones. Desdeun punto de vista psicodinámico, esta orientación hacia los actos personal es puede representar una profunda al ienación respecto del propio yo, pero esimportanterecal car quedichas interpretaciones de la responsabilidad son construcciones culturales y no una cuestión deidiosincracia. Sin lugar adudas, es evidentequeexisteunasimilitud entre este modo de justificar el comportamiento ilegal queasumeel delincuentey las implicancias de un marco de referencia "sociológico" o una "filosofía del derecho" humana. ${ }^{5}$ No es la validez deesta orientación lo quenos interesa desarrollar en esteartículo, sino su función dedesviar la culpa queimplica toda violación denormas sociales, y su relativa independencia respecto de la estructura de la personalidad. ${ }^{6} \mathrm{Al}$ aprender a reconocer que no actúa "libremente" sino por la influenciadefactores externos, el delincuenteprepara el terreno para su desviación del sistema normativo dominantesin necesidad de un ataque frontal alas normas.

La negación del daño. La segunda técnica deneutralización secentraen el daño queimplica un delito. El derecho penal establecela distinción entre delitos que son mala in se y aquellos que son mala prohibita, es decir, entre actos que son en sí mismos "mal os" y aquellos queson ilegal es pero no inmorales. El delincuente puedehacer la misma distinción al evaluar la "maldad" de su comportamiento. Parael delincuente, no obstante, la "mal dad" deun acto puededepender del hecho de si alguien sufrió o no algún daño por su desviación, lo cual puede ser interpretado de muchas maneras. Un delincuente puede definir un acto devandal ismo, por ejemplo, simplemente como una "travesura"; después de todo, puede argumentarse, los dueños de los bienes que se destruyeron pueden soportar los daños ocasionados. De modo similar, el robo de autos puede considerarseun "préstamo", y las pel eas callejeras, discusiones privadas o duelos acordados voluntariamentepor las partes, y por lotanto, deninguna incumbencia para la sociedad. No pretendemos sugerir que esta técnica de neutralización, denominada la negación del daño, implique explícitamenteunalógica determinada. Por el contrario, sostenemos que el delincuente, frecuentementey deun modo confuso, sienteque

${ }^{5}$ A través de numerosas observaciones, se advirtió que muchos delincuentes parecen tener un conocimiento sorprendente de explicaciones sociológicas y psicológicas de su comportamiento y son hábiles al destacar el rol causal de su entorno de pobreza.

${ }^{6}$ Es posible, por supuesto, que ciertas estructuras de la personalidad puedan aceptar algunas técnicas de neutralización con más facilidad que otras; sin embargo, este punto aún no ha sido estudiado en profundidad. 
su comportami ento, en real idad, no ocasiona daños importantes, a pesar deque contradicela ley. Así como el vínculo entre el individuo y sus actos puede quebrarse mediante la negación de la responsabilidad, también puedequebrarseel víncul o entrelos actos y sus consecuencias, mediantela negación del daño. Puesto quela sociedad a veces coincide con el delincuente, por ejemplo, en cuestiones como "hacersela rata" o "hacer una jugarreta", entre otros, se confirma la idea deque laneutralización delos controles sociales quehace el delincuentepor medio del apartarse delas normas es una prolongación de prácticas comunes más queun gesto de oposición.

La negación de la víctima. Incluso si el delincuenteacepta la responsabilidad desus actos desviados y está dispuesto a admitir que estos implican un daño, la indignación moral con uno mismo, y la de los otros, puede neutral izarse al insistir en que, a la luz de las circunstancias, el dañono es un mal. El daño, puedesostenerse, no es real menteun daño. Por el contrario, esunaforma justa de retribución o castigo. A través de un proceso mágico, el delincuente asume el rol de vengador, y la victima se transforma en el delincuente. Ataques a homosexuales, oaquienes se sospecha que lo son, ataques a miembros de minorías quesediceestán "fuera delugar", actos de vandal ismo como venganza contra un maestro o una autoridad del colegio a los que considera injustos, robos al dueño deshonesto de un negocio, todos pueden percibirse como daños que, a los ojos del delincuente, se infligen a un transgresor. Como dijo Orwell, el tipo decriminal admirado por el públicoen general probablemente hacambiado alo largo del tiempo y Raffleyanoes un héroe ${ }^{7}$, pero Robin Hood, y sus derivados en nuestros días, como, por ejemplo, un detective tenaz que busca que se haga justicia por fuera de la ley, aún atraen a la imaginación popular, y el delincuente puedever sus actos como partedeun rol similar aéste.

\footnotetext{
${ }^{7}$ George Orwell, Dickens, Dali, y otros, New York: Reynal , 1946.
}

Negar la existencia de la víctima, entonces, al transformarla en una persona quemerecesufrir un daño, es una forma extrema del fenómeno que acabamosdemencionar, a saber, el reconocimiento por partedel delincuentedelos objetos adecuados o inadecuados desus actos delictivos. Sin embargo, y en otro sentido, el delincuente también puede negar la existencia de la víctima, de acuerdo con las circunstancias del acto delictivo. Hastatanto la victima no esté físicamente presente, sea desconocida o de una vaga abstracción (comosuele suceder en los casos dedel itos contra la propiedad), el conocimiento dela existencia de la victima se debilita. Las normas internalizadas y las anticipaciones delas reacciones de los otros deben activarse de un modo $u$ otro, en tanto vayan a funcionar como patrones deconducta. Es posible queun conocimiento vago dela víctimajuegueun papel importanteen determinar si esteproceso se activa ono.

La condena a quien condena La cuarta técnica de neutralización parecería implicar la condena a quienes condenan o, como lo parafrasearon Corkle y Korn, el rechazo a quien rechaza (McCorkle; Korm, 1954, p.88-98). El delincuentetraslada el foco deatención desdesus propios actos desviados a los motivos y el comportamiento de quienes desaprueban su violación de la ley. El delincuente puede al egar que quienes lo van a condenar son hipócritas, desviados encubiertos, o que el rencor personal los incita a actuar así. Esta orientación respecto del mundo que cumple la ley puede resultar particularmenteimportantecuando seendurecey transforma en un encarnizado cinismo contra quienes tienen la función de hacer cumplir o expresar las normas delasociedad dominante. Por ejemplo, puede decirse que los policías son corruptos, estúpidos o crueles; los maestros siempretienen sus favoritos y los padres siempre se "desquitan" con sus hijos. A través de una sutil prolongación, la recompensa por cumplir con la ley (por ejemplo, el éxito material) seconvierteen una cuestión detireo afloje o de suerte, y, de este modo, disminuyen aún más la importancia de 
quienes están del lado dequienes cumplen con la ley. La validez de este punto de vista no es demasiado importante, ya quesu función consiste en dar vuel ta o desviar las sanciones negativas que conllevalaviolación delasnormas. El delincuente, en realidad, cambia el tema de conversación en el "diál ogo" entresus propiosimpul sos dedesviación y las reacciones de los otros; $y$, al atacar a los otros, lo "mal o" desu propio comportamiento sereprime o sepierdedevista con mayor facilidad.

La apelación a lealtades superiores. Quinto, y último, el control social interno o externo puede ser neutral izado mediante el sacrificio de las demandas dela mayoría dela sociedad en pos delas demandas degrupos sociales más pequeños a los que pertenece el delincuente, por ejemplo, sus hermanos, su pandilla o su círculo deamigos. Es importante recalcar que el delincuente no necesariamenterepudia los mandatos del sistema normativo dominante, a pesar de quesenieguea seguirlos. Por el contrario, el delincuente puede verse inmerso en un dilema que tiene que resolver, por desgracia, a expensas de violar la ley. Un aspecto de esta situación ha sido estudiado por Stouffer y Toby en su investigación sobreel conflicto entrelas demandas particularistas y universal istas y entrelos reclamos deami stad y las obligaciones sociales de carácter general. Sus resultados demuestran que "es posibleclasificar alos sujetos conformeala predisposición quetengan a el egir uno u otro de los componentes del dilema" (Stouffer; Toby, 1951). Para nuestros propósitos, sin embargo, lo másimportanteesqueladesviación respecto de ciertas normas puede surgir, no porqueserechacen dichas normas, sino porqueotras, aquellas que se juzgan más urgentes o implican una leal tad superior, seconsideran superiores. Es más, el hecho de que se crea en ambos tipos de normas es lo que le confiere sentido a nuestros conceptos dedilema y conflicto deroles.

El conflicto entrelas demandas deamistady las demandas deconformidad, o cual quier otro dilemasimilar, por supuesto, ya fuereconocido por los científicos sociales (y también por escritores) como un problemacomún delahumanidad. El delincuente juvenil, por lo general, resuelvesu dilemaal insistir en que "siemprehay queayudar a un compañero", o "nuncasedelataaun amigo"; eincluso, aún cuando esto lo ponga en serias dificultades con el orden social dominante, su elección siguesiendo conocida paraquienessupuestamentecumplen con laley. Tal vez no es común que el delincuente sea capaz de perci bir que, en real idad, actuar en nombre del gruposocial más pequeñoal queperteneceesun modo de justificación dela violación delas normas dela sociedad. Pero esto es una cuestión de grado más quedeclase.

"No quise hacerlo". "No lastimé a nadie". "El selo merecía”. “Todos semeten conmigo" "No lo hice yo solo". Podemos hipotetizar que estos slogans, o sus variantes, preparan a los jóvenes para cometer delitos. Estas "definiciones de la situación" representan gol pes tangenciales o colaterales al sistema normativo dominante, más que la creación de una ideología contraria, y constituyen una prolongación de patrones de pensamiento prevalecientes en una sociedad más queal go creado dela nada.

Las técnicas de neutralización pueden no ser lo suficientementepoderosas como para proteger totalmente al individuo de la fuerza de sus propios valores internalizados y delas reacciones dequienescumplen con la ley, ya que, comomencionamos, los del incuentes juveniles suel en padecer sentimientos decul pa o vergüenza cuando deben dar cuenta de su comportamiento desviado. $Y$ algunos delincuentes pueden estar tan aislados del mundo quecumplecon la ley, quelas técnicas de neutral ización ni siquiera entran en juego. Detodos modos, creemos que las técnicas deneutralización son decisivas para dismi nuir la eficacia del control social y descansan detrás de gran parte del comportamiento delictivo. La investigación empíricaen estaáreaes fragmentaria y dispersa, pero el trabajo deRedl ${ }^{8} \mathrm{Cressy}^{9}$ y otros proporcionó información significativa quesirvió para aclarar cuestiones teóricas y aumentar la

${ }^{8}$ Ver Redl; Wineman, 1956.

${ }^{9}$ Ver Cressey, 1953. 
cantidad deel ementos quesirvan como pruebas. Dos líneas deinvestigación parecen ser cruciales en este punto. Primero, es necesario obtener más conocimiento sobrela distribución diferencial de técnicas de neutralización como patrones de pensamiento operativo, por edad, género, clase social, grupo étnico, etc. Puedesostenersea priori que estas justificaciones de la desviación serán comprendidas con mayor facilidad por lossegmentos dela sociedad a quienes les resulta evidentela diferencia entrelos ideales sociales comunes y las prácticas sociales. También es posible, sin embargo, que el hábito de "manipular" el sistema normativo dominante - o incluso "quebrarlo" contradiga nuestras categorías sociales más imperfectasy haga referencia principal mentealos patrones deinteracción social dentro el círculo familiar. Segundo, es necesario queselleguea una mejor comprensión dela estructura interna delas técnicas de neutralización, en tanto sistema de creencias y actitudes, y su relación con varias clases decomportami ento delictivo. Algunas técnicas deneutral ización parecen adaptarsemejor a determinados actos desviados que a otros, como hemos sugerido, por ejemplo, en el caso de delitos contrala propiedad y lanegación dela víctima. No obstante, estacuestión aún no resulta muy claray requieremayor información.

De todos modos, las técnicas de neutralización parecen ofrecer una línea de investigación prometedora paraincrementar y sistematizar el bagajeteórico acerca deladelincuencia juvenil. Cuanta más información se obtenga respecto de las técnicas de neutralización, sus orígenes y sus consecuencias, mejor será para comprender tantola delincuenciajuvenil como la desviación delossistemas normativos.

(Recebido para publicação em junho de 2007) (Aceito em abril de 2008)

\section{REFERÊNCIAS}

COHEN, Albert K. Delincuencia juvenil. Glencoe, Illinois: The Free Press, 1955. 202p. Título original: Delinquent boys.

CRESSEY, D.R. El dinero de los otro. Glencoe: The Free Press, 1953. Título original: Other people's money.

KOBRIN, Solomon. Conflito de valores en distintos aspectos de la delicuencia. American Sociologial Review, Columbus,OH, n.16, p.653-661, oct., 1951. Título original: The conflict of values in delinquency areas.

McCORKLE, LIoyd W.; KORN, Richard. Resocialización meuos adentros. The Annals of the American Academy of Political and Social Science, [S.I.], n.293, p.88-98, mayo, 1954 Título original: Resocialization within walls.

REDL, Fritz; WINEMAN, David. Chicos que odian Glencoe: The Free Press, 1956. Título original: Children who hate.

STOUFFER, Samuel A.; TOBY, Jackson. Conflito de roles y personalidad. En: PARSONS, Talcott; SHILIS, Edgard A. Hacia una teoria general de la acción. Cambridge: Harvard University Press, 1951, p.494. Título original: Role conflict and personality / Toward a general theory of acting

SUTHERLAND, E.H.; CRESSES, D.R. Principios de criminología. 5.ed. Chicago: Lippincott, 1955. p.77-80. Título original: Principles of criminology.

WEBER, Max The theory of social and economic organization. Trad. A.M. Henderson y Talcott Parsons. New York: Oxford University Press, 1947. p.125.

WILLIAMS JR, Robin M. American society: a sociological interpretation. New York: Knopf, 1951, p.28. 
TÉCNICAS DE NEUTRALIZAÇÃO: uma teoría da delinqüencia

\section{Gresham M. Sykes} David Matza

Este artigo apresenta evidências que a suggest that criminals do not usually envolvemam a delinquência. Eles se envolvem na delinqüência por meio do que a delinqüência seja má, eles preten- say that their actions are justifiable for diferentes tipos de razões. Estas justifi- justifications are used before the cativas são utilizadas antes do ato delin- deliquent action, making it possible by qüente, fazendo com que este seja pos- the neutralization of the individuals' sível pela neutralização da crença dos beliefs that they are bad. indivíduos que eles são ruins.

WORDS KEY: delinquency, learning, moral

Palavras Chave: delinqüência, aprendiza- justifications, beliefs, neutralization gem, justificativas morais, crenças, téc- techniques.

nicas de neutralização.
TECHNIQUES DE NEUTRALISATION: une théorie de la délinquance

Gresham M. Sykes David Matza

Cet article met en évidence des éléments qui indiquent qu'en général les délinquants ne sont pas pour la délinquance. Ils entrent dans la délinquance en utilisant certaines "techniques de neutralisation". Même s'ils croient que la délinquance est mauvaise, ils prétendent que leurs actes sont justifiables pour diverses raisons. Ces justifications sont utilisées avant les actes de déliquance, permettant ainsi que celles-ci soient utilisées pour neutraliser l'idée des gens qu'ils sont mauvais.

Mots-CLÉs: délinquance, apprentissage, justifications morales, croyances, techniques de neutralisation. 